\title{
Electrochemical Direct Determination of Catecholamines for the Early Detection of Neurodegenerative Diseases
}

\author{
Antonella Curulli \\ Institute of Nanostructured Materials (ISMN) CNR Division 2, via del Castro Laurenziano 7, 00161 \\ Rome, Italy; E-Mail: antonella.curulli@ismn.cnr.it; Tel. +390649766743; Fax: +390649766749
}

Received: 26 February 2009; in revised form: 1 April 2009 / Accepted: 7 April 2009 /

Published: 7 April 2009

\begin{abstract}
Smart (Nano) materials with biosensing functions posses enormous potential in development of new generation of stable biosensors, chemical sensors, and actuators. Recently, there is a considerable interest in using $\mathrm{TiO}_{2}$ nanostructured materials as a filmforming material since they have high surface area, optical transparency, high biocompatibility, and relatively good conductivity. In this work, $\mathrm{TiO}_{2}$ nanostructured films were used as nanoporous electrodes to study the electron transfer mechanisms of dopamine. epinephrine and norepinephrine, in order to develop a new generation of chemical sensors. The interesting results obtained are described herein and the analytical characterization of these neurotransmitter sensors is reported.
\end{abstract}

Keywords: $\mathrm{TiO}_{2}$ nanostructured films; chemical sensors; monoamine-neurotransmitters; electrochemical transducers.

\section{Introduction}

Nanomaterials have attracted tremendeous attention in the research community, due to their unique size-dependent properties [1], which originate from the large contribution of surface atoms to the properties of nanoscale objects and from the size quantization effect [2]. Although the majority of current work on nanomaterials is focused on their optical, electrical, and magnetic properties, and the corresponding devices, a new field of biomedical applications of semiconductor and metalnanostrcutured oxides has begun to emerge. For instance, II-VI semiconductor and gold nanoparticles modified with antibodies or oligonucleotides can be used as highly stable luminescent and colorimetric tags for immunoanalysis [3]. In this work, we were interested in expanding the scope of possible biomedical applications of nanostructured materials and, in particular, $\mathrm{TiO}_{2}$ nanomaterials, which we 
have identified as potentially useful for neurochemical monitoring. This has become possible due to the utilization of a new type of nanostructured-titania, with particular films having voids and channels of different origin, with pores in the walls of the shells being one of the structural elements. These $\mathrm{TiO}_{2}$ nanostructured materials show interesting ion-sieving properties which are fundamental to create electroactive probes using the electrical-charge selectivity and permeability of these-modified electrodes (which depends on the "surface chemistry properties of these nanomaterials") [1] towards charged systems. Considering these properties, in this work we have detected several important biological probes, as dopamine, epinephrine, norepinephrine, i.e., which play a key role during excessive oxidative stress events in humans and in early diagnosis of neurodegenerative diseases.

Focusing on this last point, normal levels of dopamine in the brain allow the usual freedom of movement, whereas excess DA in the brain often creates pleasurable, rewarding feelings and sometime euphoria. One of the most well known and important effects of DA deficiency is Parkinson's disease (PD) $[4,5]$. This disease is characterized by degeneration and loss of midbrain substantia nigra neurons that produce the neurotransmitter DA, resulting in tremors at rest, inability to initiate or complete movements, muscle rigidity, postural instability and lack of facial expression [4], Neurological investigations have suggested that DA system dysfunction plays a critical role in the diagnosis of PD $[4,5]$ and at the same time, the resulting primary challenge is strictly connected to the measurement of DA and its metabolites under physiological conditions in order to obtain information for a possible early detection of Parkinson's disease

Moreover, according to other recent clinical studies [6], it seems that the content of ascorbic acid (AA) and dopamine (DA) can be used to assess the amount of oxidation stress in human metabolism, linked to cancer [7], diabetes mellitus [8], and hepatic diseases [9].

However, it is almost impossible to detect this component electrochemically by direct oxidation on a conventional electrode (i.e., glassy carbon, graphite, $\mathrm{Au}, \mathrm{Pt}$ ) because of its high overpotential and because of electrode fouling, poor reproducibility, low selectivity and poor sensitivity. Moreover, the oxidation waves of AA and DA, which coexists with AA in biological liquids, are nearly at the same potential and therefore overlapped, which results in the poor selectivity and reproducibility [10]. Thus, the ability to determine AA or DA selectively in the presence of one another has been a major goal for electroanalytical research and the development of chemical sensors for in vivo monitoring. During these last years, many efforts [11] have gone into solving this particular problem but, no satisfactory results have been obtained, especially for clinical, and bio-medical monitoring in real samples. Following this study of developing electrochemical sensors for determination of DA and AA in biological samples, this paper reports the fabrication of $\mathrm{TiO}_{2}$ nanostructured-modified Si electrodes based on film deposition on Si plates.

The strong electrocatalytic activity of the $\mathrm{TiO}_{2}$ nanomaterials toward DA, and other neurotransmitters, combined with the high ion-selectivity induced from the "chemistry surface" properties of $\mathrm{TiO}_{2}$ nanostructured oxides, gives a great analytical resolution of anodic peaks of DA and AA by using Differential Pulse Voltammetry (DPV method), which actually represents a widely used technique to detect biological molecules for clinical investigations [12].

Finally, in this work the selective determination of DA in the presence of AA as interferent has been investigated in detail and all the analytical parameters for a correct electroanalyticalcharacterization of the sensors, were reported and described. In addition, the $\mathrm{TiO}_{2}$-modified $\mathrm{Si}$ 
electrodes were applied successfully to the simultaneous determination of DA and AA in their mixtures, in order to develop chemical sensors for in vivo monitoring concerning human diseases.

\section{Experimental}

\subsection{Materials}

The present work was carried out in aqueous solutions. Purified water obtained with a Milli-Q (Millipore) water purification system was used as solvent. Dopamine, epinephrine, norepinephrine and ascorbic acid, were obtained from Sigma (St. Louis, MO, USA). All the chemicals from commercial sources were of analytical grade. The solutions were prepared using 0.1 M phosphate buffer ( $\mathrm{pH} 7.4)$. Before each electrochemical experiment, purified nitrogen gas $\left(\mathrm{N}_{2}\right.$, Rivoira Italy) was used to deoxygenate the solutions. Wafers of $\mathrm{Si}, \mathrm{p}$-Si (100) of different shape and size (i.e., minimum diameter of $1 \times 1 \mathrm{~cm}^{2}$; max. diameter of $5 \times 5 \mathrm{~cm}^{2}$ ) were purchased from Merck.

\subsection{Fabrication of Si-modified Electrodes by Nanostructured $\mathrm{TiO}_{2}$ Films}

$\mathrm{TiO}_{2}$ nanostructured films were deposited by Metal Organic Chemical Vapour Deposition (MOCVD) on Silicon substrates), according to the literature method [13]. After the deposition of nanostructured films, the $\mathrm{TiO}_{2}$-modified Si plates $(1 \mathrm{~cm} \times 1 \mathrm{~cm})$ were used as working electrode, an $\mathrm{Ag} / \mathrm{AgCl}$ was used as reference electrode, and a $\mathrm{Pt}$ wire as a counter electrode, in a three-electrode electrochemical cell [15]. In order to assure that the working electrodes have the same geometrical area $\left(0.008 \pm 0.003 \mathrm{~cm}^{2}\right)$, the $\mathrm{Si}$ plates coated by the $\mathrm{TiO}_{2}$ deposit, were fixed by a Teflon ring with a disk diameter of $1 \mathrm{~mm}$. This Teflon ring equipped with the $\mathrm{TiO}_{2}$-modified $\mathrm{Si}$ electrode, was terminated with an electrical contact consisting of a copper wire. This was directly connected to an AUTOLAB PGstat/12 potentiostat/galvanostat (Eco Chemie BV, Utrecht, Netherlands) with a metallic crocodile (banana) clip. In addition, a conventional bare Glassy Carbon (GC) electrode (Model Amel CG/492/2, $2 \mathrm{~mm}$ diameter, Milan, Italy) was used as working electrode for comparison. All the electrochemical measurements were carried out by AUTOLAB PGstat/12 potentiostat/galvanostat (Eco Chemie BV, Utrecht, Netherlands). All experiments were carried out at room temperature.

\section{Results and Discussion}

\subsection{Selective Determination of DA in the Presence of AA}

A complete material morphological and electrochemical characterisation, using several probes, and their corresponding apparent kinetic constants, $\mathrm{K}_{\mathrm{app}}$, were described in detail in our previous publications [13-15].

Because the main objective of this investigation was to selectively determine the content of DA in the presence of AA, the electrochemical response of DA and AA binary mixtures at $\mathrm{TiO}_{2}$-modified $\mathrm{Si}$ electrodes has been investigated by the DPV method with an applied potential $\mathrm{E}(\mathrm{V})$ ranging from + $100 \mathrm{mV}$ to $+400 \mathrm{mV}$ vs. $\mathrm{Ag} / \mathrm{AgCl}$ reference electrode. The Differential Pulsed Voltammograms of a 
binary mixture of $1 \mu \mathrm{M}$ DA and $1 \mathrm{mM}$ AA in 0.1 phosphate buffer solution at $\mathrm{pH} 7.4$ indicate that the interactions between nanostructured $\mathrm{TiO}_{2}$ surfaces and $\mathrm{AA}$ and DA lead to the resolution of the overlapped voltammetric wave, observed in the case of conventional GC electrode (Figure 1, dashed line), into well defined peaks at $+280 \mathrm{mV}$ and $+380 \mathrm{mV}$, corresponding to the oxidation of AA and DA, respectively (Figure 1, continuous line).

Figure 1. Differential pulse voltammogram of $1 \mu \mathrm{M}$ DA in $1 \mathrm{mM}$ AA solution, in $0.1 \mathrm{M}$ phosphate buffer, $\mathrm{pH}$ 7.4; at $\mathrm{GCE}$ (dashed line) and at $\mathrm{TiO}_{2}$-modified $\mathrm{Si}$ electrode (continous line).

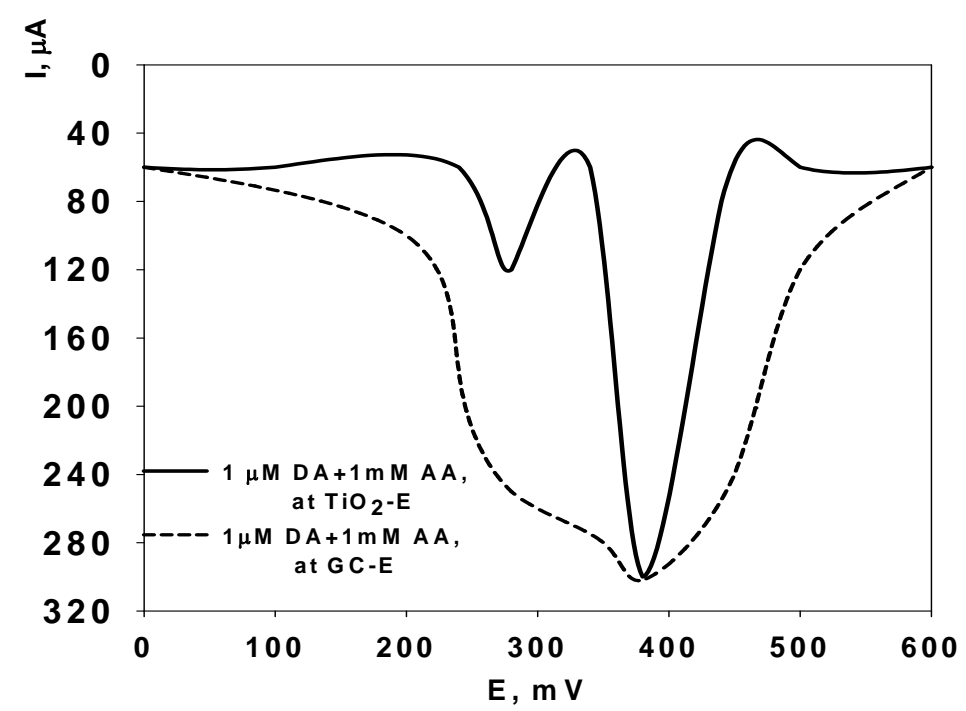

The shift of the anodic peak potentials $\left(\mathrm{E}_{\mathrm{pa}}\right)$ and the formation of the described well resolved peaks is due to the different interaction of $\mathrm{DA}$ and $\mathrm{AA}$ with $\mathrm{TiO}_{2}$ electrodes, even in the presence of a large amount of AA interferent (i.e., AA concentration $\approx$ one order of magnitude higher than that of DA in the binary mixture, as in the real biological samples) [12]. The separation between the two peak potentials is $100 \mathrm{mV}$ which is large enough for the selective determination of DA in the presence of AA, and also for the simultaneous determination of DA and AA in their mixtures. An important issue that needs to be taken into consideration is the electrocatalytic oxidation of AA by DA [16-19]. The electrooxidation of DA in the presence of AA results in a homogeneous catalytic oxidation of AA. The oxidized DA, dopamine-o-quinone, is chemically reduced by AA to DA, which can be reoxidized at the electrode surface, thus, the oxidation of AA is affected by DA (and "viceversa"). Therefore, eliminating this catalytic reaction should be necessary for the accurate determination of DA. For this purpose, considering the predominantly electrostatic nature of the size selectivity in porous $\mathrm{TiO}_{2}$ nanostructured films [13-15], one can take advantage of the difference in the ionization state and in the characteristic charge of the permeating ions (e.g., dopamine and ascorbic acid). Provided a sufficient space charge exists inside the nanostructured channels, a $\mathrm{Si}$ electrode coated with a $\mathrm{TiO}_{2}$ nanostructured layer may behave as if it could be considered simultaneously in the "open" state for dopamine and in the "closed" state for ascorbic acid. This makes possible the selective enhancement of the permeation of positively charged dopamine and retardation of the transport of negatively charged ascorbic acid. All measurements were made at $\mathrm{pH} 7.4$ which represents the physiological value of $\mathrm{pH}$ parameter in biological systems. At this $\mathrm{pH}$ value, $\mathrm{TiO}_{2}$ functionalized nanostructured films are 
negatively charged and, therefore, the diffusion part of the double layer is made up primarily by cations, as required for the separation of positively charged dopamine and negatively charged ascorbic acid [13-15]. The ratio between the dopamine and ascorbic acid signals changes from 1:3 for a native $\mathrm{GC}$ bare surface electrodes [12] to 10:1 for a $\mathrm{TiO}_{2}$ nanostructured-modified $\mathrm{Si}$ electrode, which give an overall 20 -fold enhancement of the selectivity between these substances.

\subsection{Detection of Neurotransmitters at $\mathrm{TiO}_{2}-$ modified Si Electrodes: Electroanalytical Performances and Characterization}

A more detailed evaluation was performed with respect to the analytical performance of the $\mathrm{TiO}_{2}-$ modified Si electrodes for measuring dopamine, epinephrine, and norepinephine neurotransmitters, which have particular relevance for clinical analysis and biosensor development. The calibrations of these three neurotransmitters at $\mathrm{TiO}_{2}$-modified $\mathrm{Si}$ electrodes were obtained by Differential Pulse Voltammetry (DPV) with a pulse amplitude of $50 \mathrm{mV}$; a pulse width of $60 \mathrm{~ms}$; a scan rate of $50 \mathrm{mV} / \mathrm{s}$; a pulse interval of $200 \mathrm{~ms}$; and a sampling time of $20 \mathrm{~ms} ; \mathrm{E}_{\mathrm{i}}=+100 \mathrm{mV}$; and $\mathrm{E}_{\mathrm{f}}=+400 \mathrm{mV}$, with an applied potential $\mathrm{E}(\mathrm{V})$ ranging from $+300 \mathrm{mV}$ to $+600 \mathrm{mV}$ (see Figure 2, showing the dopamine detection)

Figure 2. Differential pulse voltammograms of various concentrations of DA (ranging from $0.01 \mu \mathrm{M}$ to $1 \mu \mathrm{mol} / \mathrm{L}$ ) in $1 \mathrm{mM}$ AA solution.

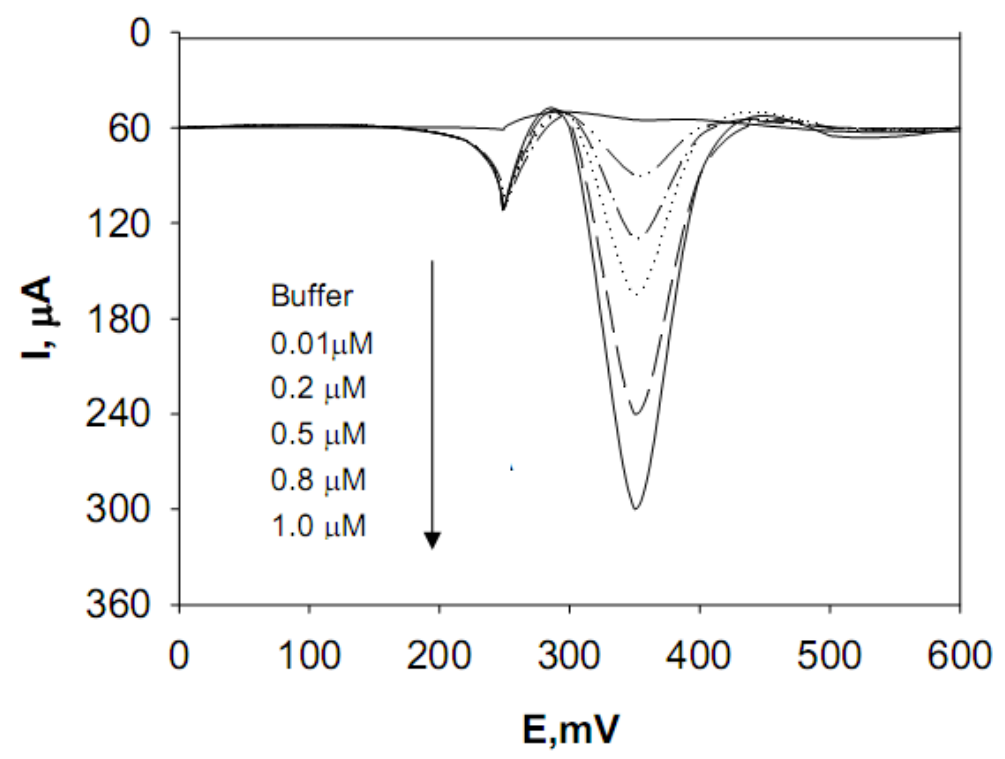

Analytical parameters, such as the linearity range, detection limit, reproducibility, and linear regression equations found for the $\mathrm{TiO}_{2}$-modified $\mathrm{Si}$ electrodes, are reported in Table 1. Overall the results demonstrated the superior behavior of the $\mathrm{TiO}_{2}$ nanostructured-modified $\mathrm{Si}$ electrodes relative to that of bare GCEs used to measure the same neurotransmitters. In particular, the Si electrodes assembled with $\mathrm{TiO}_{2}$ nanostructured films, were able to detect dopamine, epinephrine, and norepinephrine with detection limits an order of magnitude lower, relative to that found for bare GCEs tested under the same conditions. 
Table 1. Analytical parameters for $\mathrm{TiO}_{2}$-modified $\mathrm{Si}$ electrodes toward dopamine, epinephrine, and norepinephrine detection. Differential Pulse Voltammetric calibrations in $0.1 \mathrm{M}$ phosphate buffer, $\mathrm{pH} 7.4(20 \mathrm{~mL})+1 \mathrm{mM}$ AA.

\begin{tabular}{|c|c|c|c|c|c|c|}
\hline \multirow{3}{*}{ Neurotransmitters } & $\begin{array}{l}\text { Linear range of } \\
\text { concentration }\end{array}$ & $\begin{array}{c}\text { Linear regression } \\
\text { equations }\end{array}$ & LOD & RSD & Sensitivity & $\begin{array}{c}\text { Response } \\
\text { time }\end{array}$ \\
\hline & \multirow{2}{*}{ 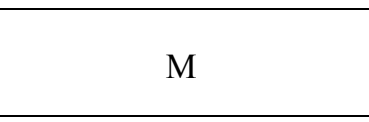 } & \multirow{2}{*}{$\mathrm{I}_{\mathrm{pa}} \mathrm{a}(\mu \mathrm{A})$ vs. $\mathrm{C} /(\mu \mathrm{M})$} & $(\mathrm{S} / \mathrm{N})=3$ & $(\mathrm{~N}=30)$ & $\mu \mathrm{A} \quad \mathrm{cm}^{-2}$ & \\
\hline & & & $\mathrm{M}$ & $(\%)$ & $\mu \mathrm{M}^{-1}$ & $\mathrm{~S}$ \\
\hline Dopamine & $1.00 \times 10^{-8}-1.00 \times 10^{-4}$ & $\begin{array}{c}80.00+0.98 \\
(\mathrm{r}=1.00)\end{array}$ & $1.00 \times 10^{-8}$ & 1 & 122.50 & 10 \\
\hline Epinephrine & $3.00 \times 10^{-8}-1.00 \times 10^{-4}$ & $\begin{array}{c}88.00+0.95 \\
(\mathrm{r}=0.99)\end{array}$ & $3.00 \times 10^{-8}$ & 2 & 118.75 & 12 \\
\hline Norepinephrine & $5.00 \times 10^{-8}-1.00 \times 10^{-4}$ & $\begin{array}{c}90.00+0.97 \\
(\mathrm{r}=0.98)\end{array}$ & $4.00 \times 10^{-8}$ & 4 & 121.25 & 11 \\
\hline
\end{tabular}

The detection limit (LOD) was defined as a signal-to-noise ratio of $3(\mathrm{~S} / \mathrm{N})=3$. The sensitivity was determined as the slope of calibration curve $\left(\mu \mathrm{A} \mu \mathrm{M}^{-1} \mathrm{~cm}^{-2}\right)$. The response time of these chemical sensors was evaluated as the time necessary to reach the peak current value, from the current background (I, $\mu \mathrm{A})$ referred level.

Experimental conditions of DPV measurements were described in Experimental section in the text. For comparison with the $\mathrm{TiO}_{2}$-modified $\mathrm{Si}$ electrode data given in Table 1, the parameters obtained for dopamine using the reference system, were as given in Table 2.

Table 2. Analytical parameters for GC bare electrodes toward dopamine, epinephrine, and norepinephrine. Differential Pulse Voltammetric calibrations in $0.1 \mathrm{M}$ phosphate buffer, pH $7.4(20 \mathrm{~mL})+0.01 \mathrm{mM} \mathrm{AA}$.

\begin{tabular}{lccccc}
\hline Neurotransmitters & $\begin{array}{c}\text { Linear range of } \\
\text { concentration }\end{array}$ & $\begin{array}{c}\text { Linear regression } \\
\text { equations }\end{array}$ & LOD & RSD & Sensitivity \\
\hline GC bare electrode & $\mathrm{M}$ & $\mathrm{I}_{\mathrm{pa}} /(\mu \mathrm{A}) \mathrm{vs.} \mathrm{C} /(\mu \mathrm{M})$ & $(\mathrm{S} / \mathrm{N})=3$ & $(\mathrm{~N}=10)$ & $\mu \mathrm{A} \mathrm{cm}^{-2} \mu \mathrm{M}^{-1}$ \\
\hline Dopamine & $3.7 \times 10^{-7}-1.0 \times 10^{-4}$ & $1.522+0.154$ & $3.0 \times 10^{-7}$ & 3 & 18.0 \\
Epinephrine & $7.5 \times 10^{-7}-1.0 \times 10^{-4}$ & $0.989+0.106$ & $5.0 \times 10^{-7}$ & 5 & 11.7 \\
Norepinephrine & $8.4 \times 10^{-7}-1.0 \times 10^{-4}$ & $0.081+0.125$ & $7.4 \times 10^{-7}$ & 6 & 12.3 \\
\hline
\end{tabular}

A bare Si electrode was not used as reference systems because no electrochemistry was observed for DA, epinephrine, and norepinephrine investigated here under the same experimental conditions of $\mathrm{TiO}_{2}$-modified $\mathrm{Si}$ electrodes, by cyclic voltammetry and DPV methods, consequently a bare GC electrode has been used as reference system.

At a bare GCE, the corresponding values were a detection limit of $3.0 \times 10^{-7} \mathrm{M}$, a linearity range of $3.7 \times 10^{-7}-1.0 \times 10^{-4} \mathrm{M}$, and a linear regression equation $\mathrm{Ipa} / \mu \mathrm{A}=1.522+0.154 \mathrm{C} / \mu \mathrm{M}$ (correlation coefficient $r=0.99)$. From these data, the detection limit ranging from to $1.0 \times 10^{-8} \mathrm{M}$, reported here for dopamine at these $\mathrm{TiO}_{2}$-modified $\mathrm{Si}$ electrodes is very interesting (one order of magnitude compared to GC bare electrodes, the reference system) compared other electrochemical probes described in literature [11,12,16-19]. The electroanalytical performances observed also for 
epinephrine, and norepinephrine neurotransmitters resulted better than GC bare electrodes, as reported in Table 2, with a detection limit one order of magnitude lower than the corresponding values calculated for a GC bare reference system.

\subsection{Reproducibility, Operational, and Long Term Stability of the $\mathrm{TiO}_{2}$ Based Neurotransmitter} Chemical Sensors

The electrodes show high stability toward neurotransmitters in the presence of AA, in terms of operational, and storage (Long-Term) stability. The operational stability of the chemical sensors towards all three neurotransmitters was evaluated keeping these sensors continuously working in a solution of dopamine, epinephrine, and norepinephrine $(0.01 \mu \mathrm{M})$ solutions, containing $0.01 \mu \mathrm{M} \mathrm{AA}$, in $0.1 \mathrm{M}$ phosphate buffer solution at $\mathrm{pH} 7.4$, and renewing these solutions every morning. Also in this case the signal, continuously recorded by DPV, showed that during the first 6 hours the analytical signal displayed a $1 \%$ decrease, and in the next 24 hours only $2 \%$. The recorded oxidation current, at $72 \mathrm{~h}$ (corresponding to 3 days) showed only a $3 \%$ decrease vs. the original oxidation current values and over 3 days, $17 \%$.

The storage stability of the chemical sensors in solution was evaluated at $+4{ }^{\circ} \mathrm{C}$ and a RT. The response to dopamine, epinephrine, and norepinephrine $0.01 \mu \mathrm{M}$ solutions containing $0.01 \mu \mathrm{M} \mathrm{AA}$ of 3 sensors, stored at $+4{ }^{\circ} \mathrm{C}$ when not in use, and tested every 2 weeks for 10 weeks (over 2 months, 70 days) showed an average decrease of $40 \%$ of the initial current value. Another three electrodes were stored at room temperature during 4 weeks and tested every 2 days. The response to dopamine, epinephrine, and norepinephrine $0.01 \mu \mathrm{M}$ solutions containing $0.01 \mu \mathrm{M}$ AA of the three sensors was found to be $55 \pm 10 \%$ of the original one at the end of the period.

Figure 3. Storage stability in a solution of dopamine, epinephrine, and norepinephrine $(0.01 \mu \mathrm{M})$ solutions, containing $0.01 \mu \mathrm{M} \mathrm{AA}$, in $0.1 \mathrm{M}$ phosphate buffer solution at $\mathrm{pH}$ 7.4 .

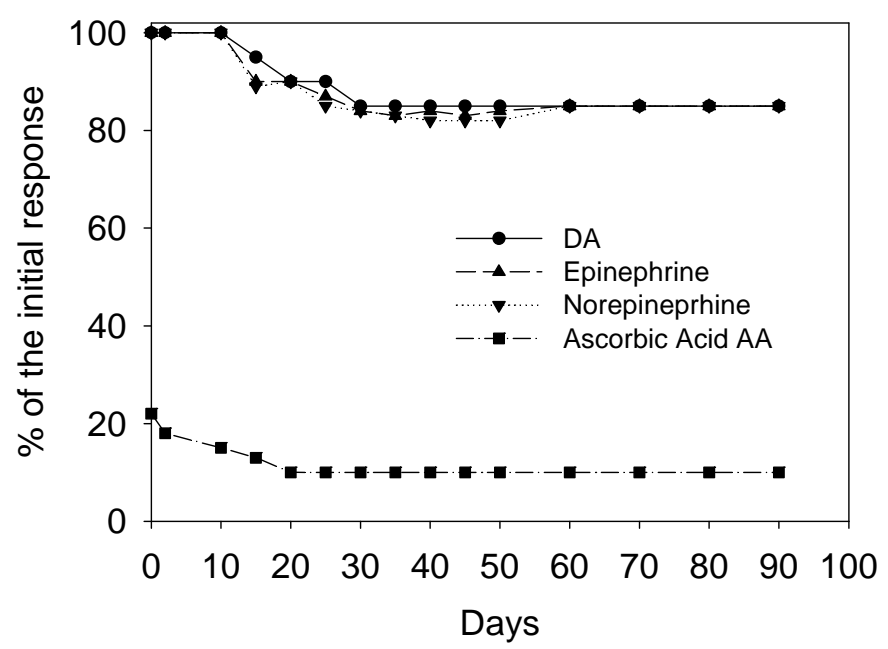

Figure 3 shows the occasional response obtained for dopamine, epinephrine and norepinephrine $\left(0.01 \mu \mathrm{M}\right.$ solutions containing $0.01 \mu \mathrm{mol} \mathrm{L}{ }^{-1} \mathrm{AA}$ in $0.1 \mathrm{M}$ phosphate buffer, $\left.\mathrm{pH} 7.0\right)$ of 3 different chemical sensors which, during a period over 2 months, have been routinely tested for dopamine, 
epinephrine and norepinephrine. After a large number of measurements (300) for each sensor, an average response decrease of $40 \%$ was observed (see Figure 3). Again several examples of neutransmitters sensors present in literature could be considered [11,12,16-19], but, to our knowledge, the sensor described in this paper was more stable (over three months vs. 15 days maximum).

\section{Conclusions}

As a result of their closely packed morphology and nanoscale dimensions of the pores inside the nanostructures, $\mathrm{TiO}_{2}$ films display strong selectivity and they can be used to modify a Si platform for electrode assembly. This quality can be further optimized and tailored to various systems of interest by controlling the size and surface modification, i.e. functionalization of the nanostructured films ("surface chemistry"), owing to the exceptional versatility of the deposition techniques. In particular, in this work, we demonstrated that the size selectivity capabilities, the large surface area, the high electrical conductivity, and bio-compatibility of these films, may greatly contribute the successful detection of several compounds, i.e., inorganic molecules, and biological compounds, as neurotransmitters. For instance, here the great advantage concerns the detection of dopamine in the presence of ascorbic acid, which represents an interference problem very difficult to avoid for clinical and bio-medical investigations. Using $\mathrm{TiO}_{2}$-modified $\mathrm{Si}$ electrodes a large number of electroactive probes were detected with high selectivity, sensitivity, reproducibility, and long term stability.

In addition, using $\mathrm{TiO}_{2}$ nanostructured coatings, the poisoning of the conventional GC bare electrodes, by the products of dopamine reduction, was reduced consistently. This important result could be achieved changing many parameters during the deposition of $\mathrm{TiO}_{2}$ films, i.e., thickness, and surface functionalities [13-15]. These $\mathrm{TiO}_{2}$-modified $\mathrm{Si}$ electrodes, could open the way for their exploitation as a coating on implantable microelectrodes for in-vivo monitoring of brain activity. This aspect could significantly facilitate the understanding of chemical communication between neurons and the diagnoses of malfunctions of the nervous system (i.e., Parkinsos's disease) directly inside the brain.

\section{References and Notes}

1. Cahn, R.W. Nanomaterials: synthesis, properties and applications. Nanostruct. Mat. 1997, 8, 377-379.

2. Mackerle, J. Nanomaterials, nanomechanics and finite elements: a bibliography (1994-2004). Modeling Simul. Mater. Sci. Eng. 2005, 13, 123-158.

3. Li, M.; Wong, K.K.W.; Mann, S. Organisation of inorganic nanoparticles using biotinstreptavidin connectors. Chem. Mat. 1999, 11, 23-28.

4. Damier, P.; Hirsch E.C.; Agid, Y. Graybiel, The substantia nigra of the human brain. II. Patterns of loss of dopamine - containing neurons in Parkinson's disease. Brain 1999, 122, 1437-1448.

5. Mascia, A.; Áfra, J.; Schoenen, J. Dopamine and migraine: a review of pharmacological, biochemical, neurophysiological, and therapeutic data. Cephalalgia 1998, 18, 174-182. 
6. Genro, K.; Seiji, K.; Yukiko, N.; Keiji, S.; Kazuaki, F.; Makoto, G. Relief of oxidative stress by ascorbic acid delays cellular senescence of normal human and Werner syndrome fibroblast cells. Free Radic. Biol. Med. 2003, 35, 438-443.

7. Kuo, S.M.; Morehouse, F., Jr.; Lin, C.P. Effect of antiproliferative flavonoid on ascorbic acid accumulation in human colon adenocarcinoma cells. Cancer Lett. 1997, 16, 131-137.

8. Heitzer, T.; Finckh, B.; Albers, S.; Karoline, K.; Kohlscutter, A. Benefical effects of $\alpha$-lipoic acid and ascorbic acid on endothelium-dependent, nitric oxide vasodilation in diabetic patients: realtion to parameters of oxidative stress. Free Radic. Biol. Med. 2001, 31, 53-61.

9. Wu, Y.; Whitman, I.; Molmenti, E.; Moore, K.; Hippenmeyer, P.; Pelmutter, D.H. A lag in intracellular degradation of mutant alphal-antitrypsin correlates with liver disease phenotype in homozygous PiZZ alpha1-antitrypsin deficiency. Proc. Natl. Acad. Sci. USA 1994, 91, 90149018.

10. Ciszewski, A.;, Milczarek, G. Polyeugenol-Modified platinum electrode for selective detection of dopamine in the presence of ascorbic acid. Anal. Chem. 1999, 71, 1055-1061.

11. Wang, Z.; Liu, J.; Liang, Q.; Wang, Y.; Luo, G. Carbon nanotube-modified electrodes for the simultaneous determination of dopamine and ascorbic acid. Analyst 2002, 127, 653-658.

12. Zhang, M.; Gong1, K.; Zhang, H.; Mao, L. Layer-by-layer assembled carbon nanotubes for selective determination of dopamine in the presence of ascorbic acid. Biosens. Bioelectron. 2005, 20, 1270-1276.

13. Curulli, A.; Valentini, F.; Padeletti, G.; Viticoli, M.; Caschera, D.; Palleschi, G. Smart (Nano) materials: TiO2 nanostructured films to modify electrodes for assembling of new electrochemical probes. Sens. Actuat. B 2005, 111-112, 441-449.

14. Viticoli, M.; Curulli, A.; Cusma, A.; Kaciulis, S.; Nunziante, S.; Pandolfi, L.; Valentini, F.; Padeletti, G. Third-generation biosensors based on $\mathrm{TiO}_{2}$ nanostructured films. Mater. Sci. Eng. C: Biomimet. Supramol. Syst. 2006, 26, 947-951.

15. Viticoli, M.; Curulli, A.; Padeletti, G. Titanium oxide based hybrid material usable as an electrochem. Sensor. U.S. Patent Application No. 11/662775, October 23, 2008; p. 19.

16. Zhang, L.; Jia, J.; Zou, X.; Dong, S. Simultaneous determination of dopamine and ascorbic acid at an in-site functionalized self-assembled monolayer on gold electrode. Electroanalysis 2004, 16, 1413-1418.

17. Li, S.; Dong, S.J. Detection of neurotransmitters by a light scattering technique based on $\mathrm{n}$ seedmediated growth of gold nanoparticles. Nanotechnology 2008, 19, 095502-095508.

18. Suzuki, A.; Ivandini, T.A.; Yoshimi, K.; Fujishima, A.; Oyama, G.; Nakazato, T.; Hattori, N.; Kitazawa, S.; Einaga, Y. Fabrication, characterization, and application of Boron-doped Diamond microelectrodes for in vivo dopamine detection. Anal. Chem. 2007, 79, 8608-8615.

19. Zachek, M.K.; Hermans, A.; Wightman, R.M.; McCarty, G.S. Electrochemical dopamine detection: Comparing gold and carbon fiber microelectrodes using background subtracted fast scan voltammetry. J. Electroanal. 2008, 614, 113-120.

(C) 2009 by the authors; licensee Molecular Diversity Preservation International, Basel, Switzerland. This article is an open-access article distributed under the terms and conditions of the Creative Commons Attribution license (http://creativecommons.org/licenses/by/3.0/). 